\title{
Aprender Design na educação básica: Estudo comparativo entre o currículo inglês e uma escola brasileira, o CAP-UERJ
}

Bianca M. R. Martins

Rita Couto

\section{Resumo}

No contexto do Design, discute-se, há alguns anos, que os conhecimentos próprios desta área são relevantes para um espectro de ações mais amplo do que o rotineiramente praticado/difundido. Nesse sentido, este trabalho debate a pertinência do Design como um saber a ser aprendido na formação básica, uma vez que oportuniza o desenvolvimento de competências cognitivas importantes para a vida adulta contemporânea como a habilidade de prototipar ideias, a visão crítica a respeito da cultura material, a desenvoltura para argumentar e negociar opiniões, dentre outras. O artigo explora as ideias de alguns autores (ARCHER, 1979; BAYNES, 2010; DAVIS, 1997, 2004; CROSS, 2006, 2010,2011, MARTINS 2016, 2017) que, desde a década de 1970, discutem a pertinência do ensino do Design na educação básica. Após, esmiuçamos o caso pioneiro brasileiro de ensino do Design na formação básica que ocorre desde a década de 1970: CAp-UERJ, escola de Aplicação da UERJ. Narramos nuances desta iniciativa contando detalhes que favoreceram a sua implementação, como também comentamos os objetivos pedagógicos vislumbrados por seus implementadores. Descrevemos as orientações curriculares desta prática, comentamos e analisamos os projetos desenvolvidos e narramos a percepção dos alunos que vivenciam esta experiência. O artigo finaliza com a apreciação da vivência desta experiência por parte da professora Lula Rufino, que esteve à frente desta empreitada ao longo de 38 anos.

Palavras-Chave: Design, educação básica, ensino aprendizagem.

\begin{abstract}
In the context of Design, it has been discussed for some years that the knowledge of this area is relevant to a broader spectrum of actions than is routinely practiced / disseminated. In this sense, this work discusses the relevance of Design as a knowledge to be learned in basic education, since it allows the development of important cognitive competences for contemporary adult life as the ability to prototype ideas, the critical view regarding material culture, the competence to argue and negotiate opinions, among others. The article explores the ideas of some authors (ARCHER, 1979, BAYNES, 2010, DAVIS, 1997, 2004, CROSS, 2006, 2010,2011, MARTINS 2016, 2017) who since the 1970s have discussed the relevance of Design education in basic education. Afterwards, we explored the pioneering Brazilian case of Design education in the basic education that has been in place since the 1970s: CAp-UERJ, School of Application of UERJ. We narrate nuances of this initiative counting details that favored its implementation as we also commented on the pedagogical objectives envisioned by its implementers. We describe the curricular guidelines of this practice, comment on and analyze the projects developed, and narrate the perceptions of the students who experience this experience. The article ends with the appreciation of this experience by Professor Lula Rufino, who has been at the forefront of this project for 38 years.
\end{abstract}

Keywords: Design, basic education, teaching, learning, curriculum. 


\section{Introdução}

Bruce Archer (1922-2005), líder de pesquisa e professor do Royal College of Art (Inglaterra), desenvolveu uma série de pesquisas no que se refere ao entendimento do Design como uma Ciência e/ou Cultura e validade de sua aprendizagem no contexto escolar. Conforme Martins $(2016,2017)$, o autor parece ser unanimidade (BAYNES, 2010; DAVIS, 1997; CROSS, 2006) como um dos fundadores do discurso de que a aprendizagem do Design é tão vital no Ensino Fundamental assim como a aprendizagem das Humanidades e do raciocínio lógico, e que este campo pode contribuir significativamente para a formação básica de sujeitos a partir de um referencial consistente composto por conhecimentos e procedimentos próprios à área.

Ainda segundo Martins (2016, 2017), Archer, com outros colegas, escreveu o relatório Design in a General Education (ROYAL COLLEGE OF ARTS, 1979), em que afirma a necessidade de uma terceira cultura na educação fundamental: o Design (com D maiúsculo), área apropriada a investigar a cultura material, habilidades, experiências e o entendimento a respeito das ações de planejar, criar e prototipar (Cross, 2006). O relatório esclarece alguns aspectos da natureza dos conhecimentos e procedimentos estudados no campo do Design:

- $\quad$ O interesse principal do Design consiste na concepção e na realização de coisas novas;

- Os procedimentos do Design envolvem a apreciação da cultura material e a aplicação de ações de planejamento, criação e prototipagem;

- $\quad$ O núcleo do Design está nos estudos da linguagem da prototipagem e, por isso, é possível desenvolver nos estudantes a habilidade de prototipar;

- O Design tem seu próprio corpo de conhecimentos, modos de apreendê-los e modos de investigá-los.

Archer propôs que a prototipagem deveria ser reconhecida como a competência fundamental do Design; ele acreditava que, da mesma forma que ocorre com a numerácia (matemática) e com a literácia (humanidades), a prototipagem deveria ser amplamente aprendida na formação básica (MARTINS, 2016).

\section{O Design como uma inteligência: Design Thinking}

Em outro estudo, Nigel Cross (2010), com base na teoria das inteligências múltiplas de Gardner (1983), sugere que a habilidade em Design consiste em uma forma de inteligência. Cross baseia-se na premissa de que existem elementos significativos suficientes embutidos no Design Thinking que, tomados em conjunto, constituem uma forma de inteligência diferente, mas comparável a outras formas de inteligência de Gardner (CROSS, 2011, p. 99).

Conforme Cross (2011), o Design Thinking é um tipo específico de inteligência que pode manifestar-se em alto grau nos designers. Contudo, esta inteligência não seria restritiva a estes profissionais, pois todo ser humano possui certa habilidade para imaginar soluções, que está incorporada ao cérebro como uma função cognitiva natural. Logo, assim como outras formas de inteligência e/ou habilidade, ela pode ser inata ou manifestar-se em desenvolvimento; em alguns casos, em níveis mais elevados do que em outros. Ou seja: a inteligência em Design não é simplesmente um talento ou dom recebido. Pelo contrário: ela pode ser treinada e desenvolvida (CROSS, 2011).

Nesse sentido, além de identificar o Design como um certo tipo de inteligência, Cross (2006) procura salientar os valores intrínsecos que justificam sua aprendizagem no ensino fundamental. $\mathrm{O}$ autor resume esses valores como sendo os Designerly ways of knowing, que se justificam de três maneiras: 
O Design desenvolve habilidades inatas de solução de problemas reais mal-estruturados

- Se o raciocínio analítico dos cientistas está focado na resolução de problemas estruturados a partir da manipulação de códigos verbais e/ou numéricos, o raciocínio projetual dos designers tem como objetivo a exploração de soluções a partir da tradução de ideias e códigos abstratos em mensagens e/ou objetos concretos.

- Por isso, o raciocínio projetual do Design desenvolve nos estudantes a habilidade de trabalhar com os problemas complexos, ou seja, que lidam com a incerteza, com múltiplas dimensões e implicações, mal-estruturados (wicked problems), e que são bem diferentes dos problemas bem-estruturados abordados pelo raciocínio analítico. Conforme Cross (2011), isso pode levar a acreditar que a natureza desses problemas é mais realista, ou seja, mais próxima das questões e decisões enfrentadas pelas pessoas do dia-a-dia. Não se trata de um treinamento ou um ensino instrumental para a ação. Refere-se à formação de um sujeito hábil a compreender a natureza dos wicked problems, com competência para abordá-los, identificando sua diferença para outras classes de problemas.

- $\quad$ O Design favorece o pensamento construtivo de prototipagem de soluções, ou seja, o desenvolvimento da cognição concreta/icônica

De acordo com Cross (2011), a aprendizagem inerente ao processo projetual de busca de soluções para problemas mal-estruturados, que implicam o desenvolvimento de objetos concretos e/ou conceitos abstratos, leva à esfera de um tipo de raciocínio muito particular ao Design: o pensamento construtivo (ou, segundo Pierce, 1931, 1958, o pensamento abdutivo). Essa classe de pensamento difere daqueles mais comumente reconhecidos: indutivo e dedutivo. É o tipo do pensamento utilizado ao desenvolver protótipos de possíveis soluções.

- $\quad$ O Design oferece oportunidades para desenvolver uma ampla gama de habilidades do pensamento e da comunicação não-verbal.

- $\quad$ Cross (2011) aponta para teorias cognitivas que sugerem que o modo de cognição concreta/icônica é particularmente relevante para o Design enquanto o modo formal/simbólico é mais apropriado às Ciências. A aprendizagem do pensamento construtivo do Design favorece o desenvolvimento da cognição concreta/icônica.

- Com base nesta justificativa, pode-se reconhecer que existem áreas da cognição humana que vêm sendo muito pouco favorecidas nos modelos de educação fundamental pelo mundo afora. A abordagem da terceira cultura reside na aprendizagem da prototipagem e dos códigos fortemente presentes nas imagens, desenhos, diagramas e rascunhos que são produzidos para facilitar o raciocínio ou para comunicar ideias a outras pessoas. Isso ainda inclui o estudo da esfera da linguagem gráfica, da linguagem dos objetos e dos mapas cognitivos.

\section{O Design como Disciplina: o caso do currículo inglês}

Conforme Raizen et al. (1995), na Inglaterra o ensino do Design para crianças e jovens veio a se constituir como um movimento nacional organizado somente nos anos 80. Segundo o autor, naquele país a abordagem do Design como componente curricular foi primeiramente nomeada de Craft, Design and Technology (CDT), uma vez que emergiu da tradição do fazer manual. Num segundo momento, incorporou um viés mais construtivista, e hoje recebe o nome de Design and Technology (D\&T).

Uma vez tendo concebido o Design como um conhecimento relevante a ser aprendido na educação básica, os ingleses o incorporaram como um componente curricular obrigatório do ensino fundamental. Isso quer dizer que crianças e jovens ingleses, dos 5 aos 14 anos, aprendem, obrigatoriamente, Design assim como aprendem línguas, matemática, educação física, etc. Esse fator, conforme pesquisamos, difere do modo no qual o Design é incorporado à educação básica nos EUA e em outros países, em que ele aparece como uma 
estratégia de solução de problemas que pode ser implementada de forma transversal ao currículo em diferentes momentos e níveis de complexidade (DAVIS, 1997).

Ainda no contexto inglês, Baynes (2010) argumenta que existem dois pontos-chave que tornam a aprendizagem do Design relevante para as crianças do ensino fundamental:

a) A natureza da atividade imaginativa do Design;

b) A questão cognitiva relacionada à linguagem visual e à habilidade de prototipar.

Estes dois aspectos são abordados no currículo inglês por meio de duas disciplinas: Artes e Design e Design e Tecnologia . A primeira está mais relacionada aos domínios da apreciação artística e experiência criativa; a segunda abarca o Design como um tipo de raciocínio projetual e abordagem multidimensional de problemas reais. Ou seja: as crianças e jovens ingleses desenvolvem dos 5 aos 14 anos, dentro destas disciplinas, habilidades que estão presentes nos desafios da vida contemporânea dos adultos que vivem em grandes cidades.

Mas, se existe certo pioneirismo por parte dos ingleses em incorporar o Design ao currículo básico obrigatório, fator que sinaliza a percepção de que existe uma relação entre os tipos de conhecimentos trabalhados no Design e as demandas da formação básica dos sujeitos contemporâneos, também temos aqui no Brasil um caso similar de incorporação do Design como componente curricular obrigatório no ensino fundamental. Vejamos.

\section{Histórico do Design no CAp-UERJ}

O CAp-UERJ iniciou suas atividades no ano de 1957 vinculado à então Universidade do Distrito Federal (UDF), a partir do incentivo proporcionado por um decreto de 1946, do então Estado da Guanabara, determinando que todas as Faculdades de Filosofia, Ciências e Letras deveriam organizar seus Colégios de Aplicação, tendo em vista a necessidade de experimentação metodológica nos cursos voltados à Educação e Licenciatura. (PPP CAp-UERJ, 2012: 5)

O currículo do CAp-UERJ apresentado à época demonstrava a valorização humanística que caracterizou a criação do colégio: Português, Francês, Inglês, Matemática, Grego, História do Brasil, História Geral, Geografia, Alemão, Desenho, Espanhol, Física, Química, História Natural, Educação Artística, Latim, Educação Física, Filosofia, Literatura e Estudos Sociais. As disciplinas cursadas em cada série dependiam do curso para o qual o aluno se dirigia - clássico ou científico - a partir da opção em Pré-Letras e Pré-Engenharia. (PPP CAp-UERJ, 2012: 5)

Em 1967, dez anos após sua fundação, o CAp-UERJ foi desvinculado da Faculdade de Filosofia, Ciências e Letras, seguindo, ainda, vinculado à UERJ. Contudo, a relativa autonomia não modificou os objetivos que deram origem ao colégio, que tinha como missão, desde a sua fundação, ser uma unidade de experimentação e aperfeiçoamento metodológico e didático do ensino de nível médio e centro de treinamento dos alunos da Faculdade de Educação. (PPP CAp-UERJ, 2012: 6)

Na década de 1970, a partir de discussões a respeito de diretrizes pedagógicas para um ensino inovador e experimental, foi instituído o Ensino Fundamental e o horário integral, fatores que favoreceram o surgimento de projetos renovadores e integradores de diferentes áreas do conhecimento: Festa do Folclore, integrando Educação Física, Artística e História; apresentações de teatro, com a participação dos docentes ligados à área de Comunicação e Expressão e às Artes Plásticas; Semana Comunitária, conjugando os esforços de alunos e professores de diversos campos do conhecimento no atendimento à comunidade do entorno do colégio; organização de visitas orientadas a museus, unidades industriais e laboratórios, e também Feira de Ciências, Olimpíadas, Coral, Festival de Música, Banda Escolar e exposições permanentes de Artes Plásticas. (PPP CAp-UERJ, 2012: 7) 
Também na década de 1970, foram criados o Clube de Cinema, antiga solicitação dos alunos, o gabinete médico e salas especiais para o serviço de fonoaudiologia, que atenderia também à comunidade externa. Foram criados ainda o laboratório de fotografia e a sala de artes industriais, fator que oportunizou a entrada na grade curricular da Disciplina Design. (PPP CAp-UERJ, 2012: 8)

De acordo com Lula Rufino , o colégio sempre se propôs a ser uma instituição de educação experimental e com vistas a proporcionar novos caminhos na formação do pensamento e conhecimento de seus alunos. Segundo ela, a disciplina Design foi instituída a partir da necessidade de atendimento à Lei no ${ }^{\circ} 5692$ - que versava a respeito do currículo de $1^{\circ}$ e $2^{\circ}$ graus e, especificamente em seu Artigo $7^{\circ}$, tratava da necessidade do ensino de Educação Artística nesses segmentos. A partir dessa demanda, Rufino e um grupo de professores foram convidados pela diretora, a Profa. Maria Lúcia Weiss, para decidir quais disciplinas atenderiam à necessidade de uma formação artística. O grupo optou por implantar as disciplinas de Música, Teatro, Artes Plásticas, Fotografia, História da Arte, Coral e Banda como disciplinas fixas na grade escolar.

Segundo Rufino, todas essas disciplinas tinham como proposta apresentar para o aluno possibilidades de atuação a partir do conhecimento de diferentes linguagens expressivas - Rufino nomeia esse processo como sendo uma sondagem de aptidões. Contribuíam, ainda, para a construção do pensamento crítico para a inserção do aluno na sociedade contemporânea com o aporte de linguagens criativas.

A professora enfatiza que cada uma dessas disciplinas apresentava metodologias de aprendizagem diferentes. A intenção era diversificar o alcance da formação integral dos alunos, que, nessa época, já se consolidava a partir da jornada diária em período integral. Ainda segundo a professora, todas essas disciplinas seguem até hoje integrando a grade curricular da escola.

Rufino comenta que a disciplina Design, desde sua introdução, passou a integrar o $9^{\circ}$ ano do ensino fundamental, com 50 minutos semanais. Atualmente, a carga horária foi ampliada para 2 tempos de aula semanais consecutivos no $9^{\circ}$ ano do ensino fundamental e, ainda, no $1^{\circ}$ ano do ensino médio, representando, em cada um destes anos, 100 minutos semanais de aula de Design. Essa conquista deve-se à compreensão de que as atividades realizadas precisavam de um maior tempo de aula para a aprendizagem e execução da metodologia de projeto.

A professora comentou que por um tempo, durante a década de 2000, instituiu-se a ideia de desenvolver no CAp-UERJ uma proposta de Ensino Profissionalizante, com oficinas aos sábados pela manhã. Fizeram parte desta iniciativa oficinas de Patologia Clínica, Administração, Contabilidade e Design. Com isso, a Oficina de Comunicação Visual e Fotografia, numa perspectiva de Ensino Profissionalizante, também pôde ser vivenciada pelos alunos durante esse período. Abaixo um gráfico com a linha do tempo da consolidação da aprendizagem em Design no CAp-UERJ:

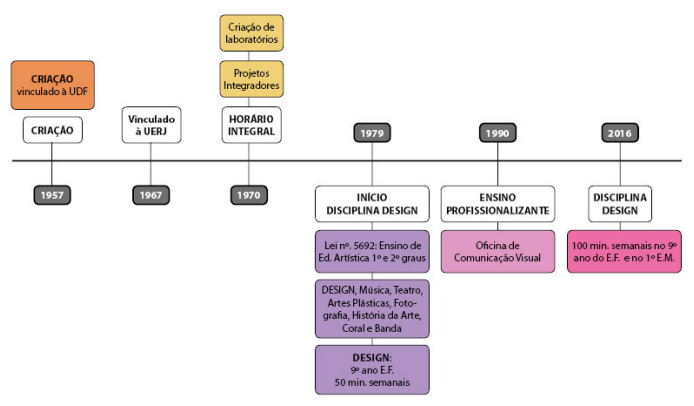

Figura 1: Linha do tempo da consolidação da aprendizagem em Design no CAp-UERJ. 


\section{Metodologia de ensino aprendizagem e projetos desenvolvidos}

A ementa da disciplina Design para o $9^{\circ}$ ano do ensino fundamental pode ser vista abaixo no original e, ao lado, com detalhes reescritos:

\begin{tabular}{|l|l|}
\hline $\begin{array}{l}\text { Nome da disciplina: } \\
\text { Design para o Ensino Fundamental }\end{array}$ & $\begin{array}{l}\text { Carga Horária total: } \\
68 \mathrm{~h} / \mathrm{a}\end{array}$ \\
& $\begin{array}{l}\text { Carga Horária semanal: } \\
1 \text { hora teórica } \\
1 \text { hora prática }\end{array}$ \\
\hline
\end{tabular}

\section{Ementa:}

- Projetar imagens com recursos gráficos, usar a tipografia e a metodologia de projeto gráfico, visando uma comunicação visual.

- Projetar imagens através de recursos gráficos tradicionais como: lápis de cor, montagem, colagem, tipografias técnicas de impressão.

- $\quad$ Fazer a transposição de imagens com recursos gráficos tradicionais para imagens digitais utilizando os softwares de imagem, scanners e programas como o CorelDraw, Photoshop e outros.

- $\quad$ Conhecer a área de trabalho profissional em que atuam os Designers Gráficos e digitais, como os projetos de Design para vários suportes: papel, fotografia, tecido, acetato, impressão gráfica, multimídia, web Design e editoração visual.

- Projetar imagens com as etapas do projeto definidas em Comunicação Visual: tempestade de ideias, rafes, layout, arte final e protótipos.

- Trabalhar em ambiente como um Estúdio, atelier gráfico e/ou Bureau Gráfico, no cargo de Assistente do Diretor de Arte: o Programador Visual Trainee. digitais.

Conhecer e utilizar o vocabulário técnico intrínseco à área de atuação dos Designers gráficos e

Utilizar o computador, scanner, a impressora, a partir de softwares e realizar projetos de imagens.

Figura 2: Ementa de disciplina Design. CAp-UERJ. Projeto Político Pedagógico CAp-UERJ. 2013. Disponível em: http://www.cap.uerj.br/site/images/stories/noticias/projeto-politico-pedagogico-1.pdf.

Observada esta ementa, pode-se dizer que a finalidade do ensino do Design no $9^{\circ}$ ano no CAp-UERJ é proporcionar uma educação Pré-profissional em Design, que consiste em:

Atividades que familiarizam os alunos com o trabalho dos profissionais de Design, replicando alguns aspectos da prática projetual desta carreira. Estas atividades são frequentemente realizadas por meio de projetos em laboratórios de Design durante os cursos de graduação na área e se direcionam à aquisição de uma habilidade conceitual ou técnica necessária para executar tais projetos. Essas experiências auxiliam os alunos na aquisição das competências necessárias para exercer uma carreira em Design (Davis, 2004: 9). 
Rufino nos forneceu os descritivos de diversas atividades projetuais desenvolvidas com os alunos nos últimos anos. Dentre elas, vale a pena citar:

- $\quad$ Projeto de ilustração para a Camiseta das Olimpíadas com o uso de técnicas de criação e digitalização de imagens que foram selecionadas por um de júri para, de fato, serem usadas nas camisetas das olimpíadas da escola;

- Desenvolvimento de ilustração original para camiseta que posteriormente foi transferida para uma camiseta. Depois, cada aluno usou sua camiseta por um dia procurando perguntar ao colega o que compreendia daquela mensagem. Após essa etapa, cada aluno descreveu em relatório o processo de recepção das mensagens pelos colegas;

- $\quad$ Projeto de elaboração de um cartão postal ilustrado, que foi enviado a um destinatário real, em que a elaboração levava em conta o relacionamento entre autor e leitor;

- Desenvolvimento de uma capa de livro com base na leitura da sinopse da obra. Em seguida, os projetos foram impressos e expostos em evento na escola;

- $\quad$ Desenvolvimento de imagens e produção impressa de embalagem e cartas para baralho;

- $\quad$ Projeto de redesign de embalagem de produto;

- $\quad$ Desenvolvimento e produção impressa de histórias em quadrinhos;

- Desenvolvimento de imagem, produção e montagem de quebra-cabeças.

Ao apreciar e discutir com Rufino a respeito das atividades desenvolvidas, percebemos que elas desenvolvem uma noção do trabalho profissional com Design, abordando processos, técnicas, suportes, etc. Contudo, notamos que um importante propósito é investigar como o público recebe os diferentes objetos desenvolvidos. Ou seja, o planejamento pedagógico da disciplina demonstra preocupação em trabalhar com o aluno o conceito de que o objeto de Design precisa ser compreendido por seu público. Seguem abaixo algumas imagens de projetos desenvolvidos em 2015.

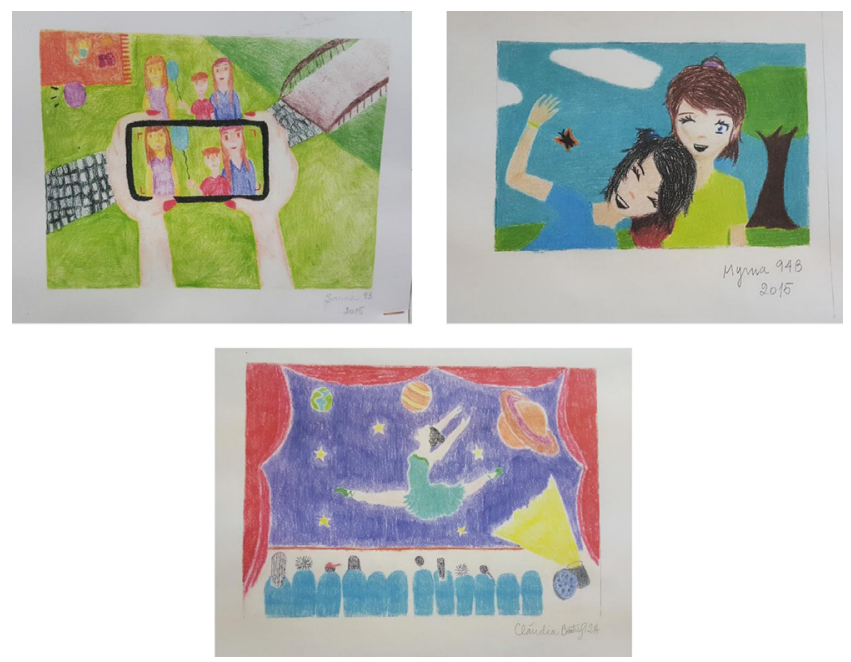

Figura 3: Alguns projetos do cartão postal ilustrado - Design $9^{\circ}$ ano, turma de 2015 de Lula Rufino CAp-UERJ. 

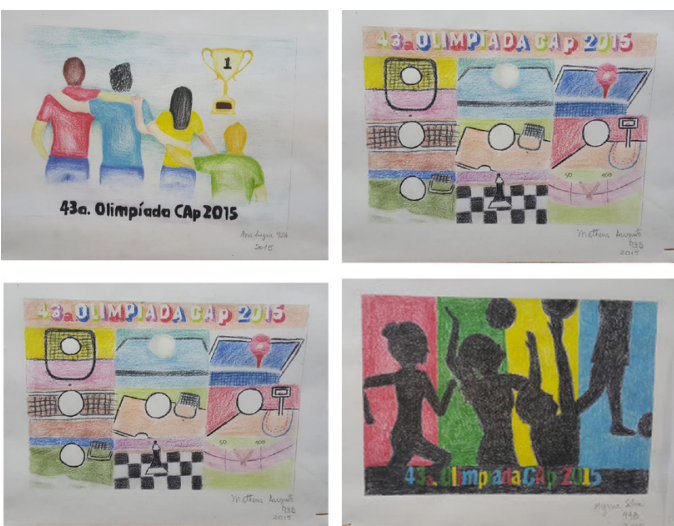

Figura 4: Alguns projetos de ilustração para camiseta Olimpíadas - Design 9ª ano, turma de 2015 de Lula Rufino CAP-UERJ.

\section{A construção do conhecimento em Design no CAP/UERJ nestes 37 anos}

A conversa com Rufino nos instigou a questionar o que os alunos aprendiam com o desenvolvimento das tarefas.
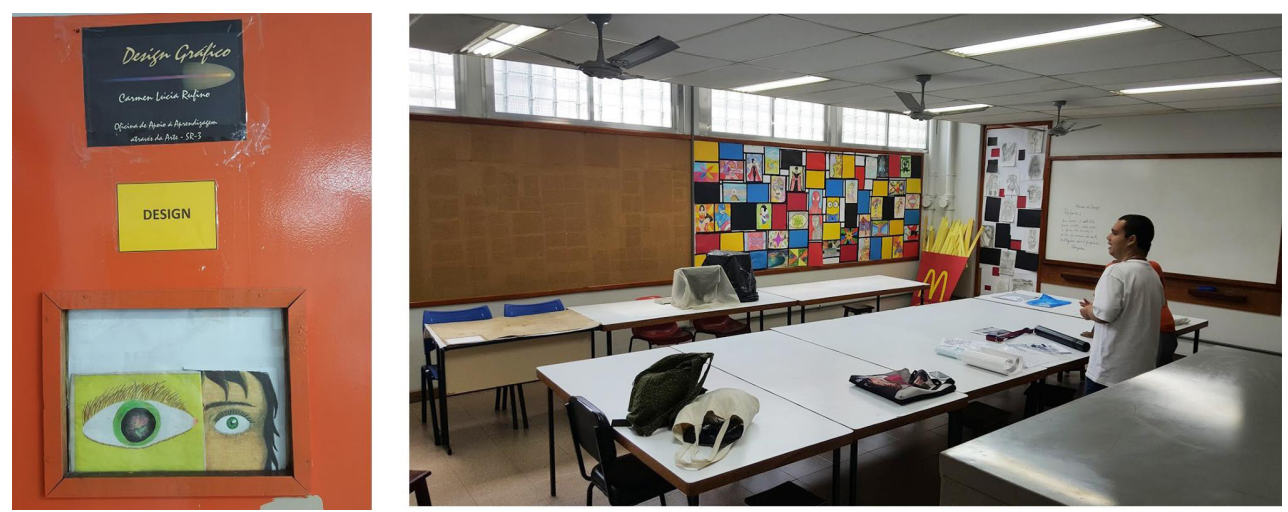

Figura 5: Detalhes da porta e do interior da sala de aula de Design CAp-UERJ

Tivemos uma surpresa positiva quando a professora Lula Rufino nos revelou que desenvolveu, durante o ano de 2015, uma pesquisa por meio de uma autoavaliação com as quatro turmas do $9^{\circ}$ ano em que lecionou. A intenção era apurar a compreensão dos alunos em relação a alguns pontos importantes do Design. Para isso, ela criou um formulário que foi respondido por 60 alunos das quatro turmas que vivenciaram a disciplina. Destacamos cinco questões do questionário que consideramos relevante comentar:

- $\quad$ que você entende quando um cliente lhe pede para criar uma imagem inédita, original, sobre um tema que sua campanha necessita, dentro dos critérios do Design Gráfico?

- Qual é a etapa mais importante num projeto de Design Gráfico para a comunicação com o público em geral?

- Por que a idade do público alvo influencia no projeto de criação de imagem no Design Gráfico? 
- $\quad$ Por que o material específico utilizado na execução da criação de imagens nos projetos de Design Gráfico é tão importante?

- Você realizou até agora quatro projetos de Design gráfico. De qual você mais gostou de realizar e por quê?

Sobre a primeira questão, percebemos que discute oportunamente o plágio, e esse tema faz uma conexão importante com a vida contemporânea, principalmente em se tratando das facilidades oferecidas no cenário digital. De forma geral, os alunos demonstram compreender a problemática do plágio e a necessidade de valorizar uma solução original, como se observa em algumas respostas abaixo (nomes fictícios):

O cliente quer uma coisa original, única e está cansado de plágios das grandes marcas. (Tereza)

Entendo que devo criar alguma coisa que possa chamar a atenção, uma criação totalmente minha que esteja adequada ao tema dado pelo cliente. (Julia)

Eu entendo que devo criar uma imagem com a minha imaginação, que ninguém tenha visto ainda, sem plágio. (Juliana)

Entendo que não devemos ter plágios e outras cópias, criando um projeto sem estereótipos e original. (Claudia)

A segunda questão fala a respeito da compreensão de mensagens uma vez que o Design é comunicação. Percebemos que as respostas são variadas, mas costumam abordar a pesquisa e a metodologia para gerar uma proposta comunicativa interessante para o público. Seguem algumas respostas sobre qual é a etapa mais importante num projeto de Design para a comunicação com o público em geral:

A pesquisa pelos temas que estão atualmente circulando pelo público-alvo. (Giovana)

A etapa da criação, pois a comunicação só é feita quando a pessoa que vê entende o que você imaginou e desenhou. (Juliana)

A parte da ideia do projeto que funciona como uma base para o projeto, o começo para qualquer desenho que se faz. (Julia)

Para a comunicação com o público-alvo são importantes pesquisas sobre este público e sobre este tema. (Isabela)

Criar ideias interessantes que atraiam o público. (João)

A terceira pergunta, sobre a idade do público e consequente linguagem visual apropriada, também apresenta um nível interessante de maturidade nas respostas. Os entrevistados, em sua maioria, parecem compreender a necessidade de adequar a linguagem visual ao perfil do público. Vejamos:

Porque cada idade tem algo que ela se interessa mais, não adianta muito fazer algo que não agrada ao público. (João)

Porque cada idade de público-alvo requer um tema diferente, por exemplo, um desenho feito para o público infantil terá uma interpretação diferente quando visto por um adulto. (Giovana)

Porque você desenha um tema que faça parte do cotidiano ou que tenha a ver com o público-alvo. (Eduardo)

Porque um trabalho para uma criança de 6 anos, por exemplo, não vale para um adolescente de 16. Tem que ser trabalhos diferentes, elaborados e construídos diferente. (Tereza)

Sobre o uso de materiais e técnicas específicas as respostas demonstram, em grande parte, que existe um entendimento da implicação deste com a qualidade do resultado. 
O material influencia muito na qualidade do projeto. Então ter um material específico é importante. (João)

O material correto auxilia e guia a confecção, criando algo bonito e profissional. (Cláudia)

A última questão trata do prazer em se expressar por meio dos recursos do Design. Os estudantes comentaram que os projetos que tinham um público específico foram melhor recebidos, pois neles os estudantes puderam perceber, concretamente, a reação deste público. Ainda foram citados projetos para concursos e um projeto para vestir uma camisa com estampa feita pelo próprio aluno.

O cartão postal, pois foi um trabalho desenvolvido para que fizéssemos uma imagem para uma pessoa importante em nossas vidas, onde pudemos fazer qualquer coisa, desde que essa pessoa entendesse. (Guilherme)

Todos, alguns foram complicados principalmente na parte da criação, mas a maneira que os projetos foram se desenrolando ficou mais simples e mais divertido também. (Tereza)

O que gostei foi a capa de livro pois deu liberdade para criar a história e desenhar meu personagem. (Henrique)

O da camisa porque é um projeto onde eu expressei meu desenho e posso utilizá-la no dia-a-dia. (Bruno)

\section{Análise da aprendizagem em Design no CAp/UERJ}

Conforme Rufino, os alunos do $9^{\circ}$ já conseguem realizar projetos gráficos passando por etapas projetuais que vão da pesquisa de similares, brainstorming, geração de alternativas até a finalização de uma proposta.

Hoje, no CAp-UERJ, nenhum aluno no $9^{\circ}$ ano do ensino fundamental confunde o campo do conhecimento ou de trabalho das Artes Plásticas com o do Design, e também posso dizer que os demais professores e os pais de alunos também entendem essas diferenças. (RUFINO, 2015)

Rufino (2015) comenta ainda que os conhecimentos para a criação e o desenvolvimento de ideias também são utilizados em projetos de outras disciplinas. Ela tem conhecimento desta potencialidade, pois o assunto é discutido por professores em reuniões de planejamento acadêmico.

Os alunos incorporam esses raciocínios, essas metodologias, e seguem, às vezes, a mesma metodologia em sequência, por exemplo, para agir num laboratório de biologia ou física, assim como também utilizam esse pensamento criativo para conseguir um resultado numa outra área de pesquisa ou projeto. (RUFINO, 2015)

Além de o Design ser aprendido e utilizado no CAp-UERJ como um tipo de raciocínio que pode ser aplicado a outras situações acadêmicas e cotidianas, o conhecimento em Design trabalhado nessa escola faz com que os alunos compreendam em que consiste a área, fator que pode contribuir para que seja escolhida como carreira a ser seguida na vida profissional.

\section{Considerações finais}

É possível fazer uma ponte entre o legado da aprendizagem em Design do CAp-UERJ - que vem sendo consolidada desde 1979 - e o currículo inglês que institui o ensino do Design na Educação Básica na década de 1980. A partir da imersão no CAp-UERJ e uma entrevista com a professora Lula Rufino, pudemos perceber que o design vem sendo trabalhado nessa escola como uma linguagem de apreciação e expressão de ideais. 
Também verificamos que ali o Design vem sendo usado como um modo de desenvolver o raciocínio projetual para que os estudantes saibam que os objetos materiais e imateriais do cotidiano são elaborados dessa forma e a partir de investigações de desejos e necessidades de públicos específicos.

Contudo, mesmo tendo no Brasil uma escola que leciona Design desde 1979, foi preciso recorrer a estudos gringos para encontrar um arcabouço teórico para discutir e reconhecer o valor de sua aprendizagem na formação básica. Infelizmente, temos o nefasto costume de olhar para fora do Brasil, buscando exemplos de situações “de ponta” que possam servir para estudos de caso. É preciso, porém, reconhecer que no CAp-UERJ temos um case importante de uma oportuna aprendizagem do raciocínio projetual do Design durante a fase escolar como forma de aprimorar um tipo de inteligência que pode ser utilizada em diversas outras ações cotidianas ou profissionais. Ou seja, temos um relevante exemplo "dentro de casa" a ser mais e melhor pesquisado. O CAp-UERJ, que vem ensinando Design na Educação Básica desde a década de 1970, está localizado na própria cidade do Rio de Janeiro, onde nasce o primeiro curso de graduação e também o primeiro curso Lato Sensu em Design.

Acreditamos que outros estudos de caso que abordam o ensino do Design na educação básica merecem um olhar mais atencioso por parte dos pesquisadores brasileiros em Design, até mesmo como um registro histórico pormenorizado das diretrizes, metodologias e conhecimentos construídos.

\section{Notas}

1. O currículo inglês para a Educação Básica foi remodelado como um todo em 2014 e, naturalmente, é foco de muitas discussões controversas.

2. Em 12 de março de 1946, o Decreto Lei 9053 do Estado da Guanabara.

3. RUFINO, Carmen Lúcia. Depoimento pessoal. Rio de Janeiro, novembro de 2016.

4. No $1^{\circ}$ ano do ensino médio o aluno opta para uma dentre as seguintes disciplinas Design, Fotografia, Artes Plásticas, Música e Teatro

\section{Referências Bibliográficas}

ARCHER, Bruce, Design as a Discipline, Design Studies, Vol 1, No 1, July 1979, pp.17-20

BAYNES, K. Models of Change: The future of Design education. In: Design and Technology Education: An International Journal. Loughborough, Vol. 15, No. 3, pgs. 10-17, 2010.

CROSS, N. Designerly ways of knowing, Springer-Verlag, London, 2006.

CROSS, N. Design Thinking: Understanding How Designers Think and Work. Oxford: Berg Publishers, 2011.

DAVIS, Meredith. et al. Design as a Catalyst for Learning. Virgínia: ASCD, 1997.

Education by Design. In: Arts Education Policy Review. Vol. 105, No. 5, May/June 2004.

MARTINS, Bianca. M R., O professor-designer de Experiências de aprendizagem: Tecendo uma epistemologia para a inserção do Design na Escola. 2016. Tese (Doutorado em Design) - Departamento de Artes e Design - Pontifícia Universidade Católica do Rio de Janeiro, PUC-Rio, Rio de Janeiro, Brasil. 2016.

MARTINS, Bianca, NOLASCO-SILVA, Leonardo. O professor-designer de experiências de aprendizagem: autoria docente e uso recursos lúdicos na formação de professores. Revista Carioca de Ciência, Tecnologia e Educação, v. 2, 2017.

RAIZEN, S. et al. Technology education in the classroom. Understanding the designed world. San Francisco: Jossey-Bass Publishers, 1995.

RUFINO, C. L. Depoimento pessoal. Rio de Janeiro, novembro de 2016 